\title{
IMPLEMENTASI IPTEK BAGI MASYARAKAT (IbM) PADA PENGRAJIN MINIATUR MENARA
}

\author{
Oleh: \\ Rina Fiati $^{1}{ }^{*}$, Esti Wijayanti ${ }^{2}$ \\ ${ }^{1,2}$ Progam Studi Teknik Informatika, Fakultas Teknik, Universitas Muria Kudus \\ *rina.fiati@umk.ac.id
}

\begin{abstract}
Abstrak
Tujuan dari kegiatan Pengabdian pada Masyarakat (PKM) ini adalah mengembangkan dan membentuk sekelompok masyarakat yang mandiri secara ekonomis., meningkatkan pengrajin miniature menara dalam merebut peluang pasar melalui peningkatan kualitas produk dan pemasaran miniatur menara. Target khusu yang akan didapatkan mitra adalah meningkatkan desain kerajinan miniature menara sehingga dapat meningkatkan penjualan. Metode yang digunakan sebagai solusi mengatasi permasalahan tersebut adalah pendampingan serta penguatan akan proses produksi. Pemecahan solusi pada proses produksi agar menghasilkan produk berkualitas dan pelatihan e -commercebagi pengrajin handycraf miniature menara di Desa Bacin Kab.kudus. Hasil kegiatan ini menunjukkan bahwa mitra merasa senang mendapatkan pengetahuan teknologi informasi komputer, pengenalan dan pelatihan internet dan pengelolaan website, dan pembuatan e commerceuntuk pengrajin miniature menara untuk memasarkan produk kerajinan secara e commerce.
\end{abstract}

Kata Kunci: IbM, Pengrajin Miniature Menara, E-Commerce, Teknologi, Informasi

\begin{abstract}
This activity of Community Service aims to develop and form an economically independent group of society, to enhance the development of minaret miniature's craftsmen in seizing market opportunities by means of improving its product quality and marketing. The specific target expected to reach by the partner-craftsmen is to improve the craft design so as to develop its sales. The method used as a solution to overcome these problems is the accompaniment and strengthening of the production process. The problem solving is in its production process, i.e. to produce quality products and e-commerce training for minarets miniature's craftsmen in Bacin Village, Kudus Regency. The results obtained from the activity are Introduction of computer information technology to craftsmen-partners, Introduction and training of internet and website management, making e commerce for minaret miniature's craftsmen to market their products on ecommerce basis.
\end{abstract}

Keywords: IbM, minaret miniature's craftsmen, E-Commerce, technology, Information

\section{PENDAHULUAN}

Perkembangan industri dewasa ini telah memberikan sumbangan besar terhadap perekonomian Indonesia. Di lain pihak hal tersebut juga memberi dampak pada lingkungan akibat buangan industri maupun eksploitasi sumber daya yang semakin intensif dalam pengembangan industri. Lebih lanjut dinyatakan harus ada transformasi kerangka kontekstual dalam pengelolaan industri, yakni keyakinan bahwa operasi industri secara keseluruhan harus menjamin sistem lingkungan alam berfungsi sebagaimana mestinya dalam batasan ekosistem lokal hingga biosfer. Efisiensi bahan dan energi dan air dalam pemanfaatan, pemrosesan, dan daur ulang, akan menghasilkan keunggulan kompetitif dan manfaat ekonomi. Perkembangan di bidang industri ini memacu pertumbuhan industri-industri di suatu negara, dengan jenis yang beragam mulai dari industri rumah tangga sampai industri besar.

Saat ini industri kerajinan tangan banyak dilakukan oleh usaha kecil dan menengah. Usaha ini kebanyakan ditopang oleh masyarakat kecil. Mungkin itu sebabnya industri kerajinan terus tumbuh, apalagi di Indonesia yang memiliki budaya sangat beragam, yang menjadi tempat tumbuhnya industri kerajinan. Salah satu industri rumah tangga yang banyak mendapat sorotan dari segi lingkungan di Desa Bacin adalah industri kerajinan miniatur menara dari bahan kayu. Semakin pesatnya perkembangan industri kecil soufenir, akan berdampak positif bagi 
kemajuan yang membawa peningkatan pendapatan ekonomi masyarakat kecil. Industri kerajinan miniature menara yang terletak di Desa Basin Kecamatan Kota Kabupaten Kudus ini merupakan kategori industri kecil atau industri rumah tangga.

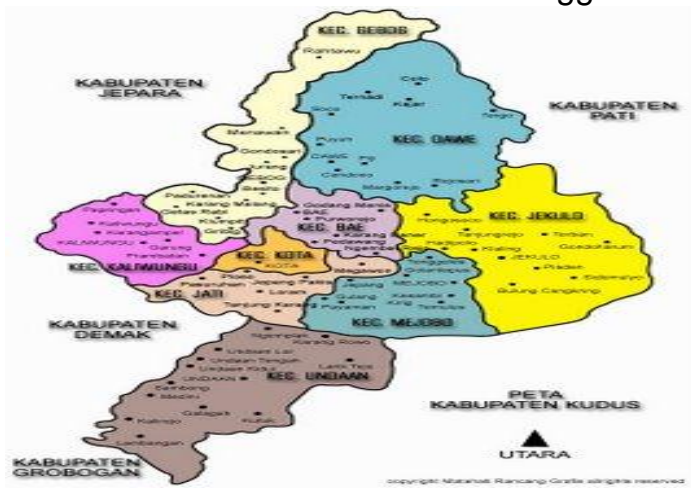

Gambar 1. Peta Administratif Kabupaten Kudus

Berdasarkan analisis situasi pasar yang biasanya kita sebut market share adalah pasar yang selama ini ada biasanya dikuasai oleh perusahaan besar. Sehingga para penguasa kecil atau yang disebut usaha kecil dan menengah (UMKM) mengalamai kesulitan dalam pemasaran yang tradisional terhadap keseluruhan penjualan seluruh pesaing. Dalam hal ini pemilik produk miniature menara megunakan metode penjualan tradisonal yang mana penjual dan pembeli harus bertemu dalam waktu yang bersamaan dan melaksanakan transaksi jual beli.

Sosial Media Content Marketing (SMCM) memainkan peran penting dalam kesediaan merek karena merupakan media untuk konsumen untuk mendapatkan informasi tentang merk (Ahmad N.S., 2015). Pada saat ini, para pebisnis cenderung menggunakan media pemasaran social untuk memasarkan tentang merk mereka kepada konsumen. Melalui social platform media, mereka terlibat dengan konsumen mereka dan membangun interaksi aktif antara mereka. Oleh karena itu, sangat penting untuk perusahaan untuk memiliki konten pemasaran yang baik untuk menarik lebih banyak pelanggan untuk mengunjungi halaman mereka, mengikuti berita pembaruan dan akhirnya mengulangi pembelian.

Pada umumnya industri kecil kerajinan soufenir belum mempunyai catatan-catatan atau perhitungan seberapa jumlah masukan (bahan baku, biaya tenaga kerja, dan biaya overhead produksi) yang sebenar-benarnya untuk setiap kali tahapan proses. Sehingga beberapa industri kecil skala rumah tangga yang hampir sebagian besar kurang memperhatikan penyebab turunnya kualitas, bagaimana alternatif langkahnya serta rencana aksi yang akan dilakukan dan bagaimana pengelolaan serta pemasaran pasca produksi. Disisi lain mereka juga kurang memperhatikan mengenai masalah tata letak peralatan dan layout ruang produksi yang dilihat cukup semrawut dan kotor sehingga terkadang menyebabkan hasil produksi terkena dampak lingkungan tersebut sehingga menurunkan kualitas produksi.

Permasalahan.

Permasalahan yang terjadi pada mitra adalah yaitu pemilik Miniature Menara Kudus melakukan transaksi penjualan dan pembelian secara tradisonal yang pastinya akan mengalami kesulitan dalam hal pemasaran karena tantangan masyarakat ekonomi global sudah berkembang yang mana pada era ini mitra harus mengikuti perkembangan teknologi yang ada yaitu dengan memasarkan barang produksi kemasyarakat luar tidak hanya pada pasar local. Melihat dari permasalahan tersebut maka dapat dirumuskan beberapa permasalahan yang harus diselesaikan untuk dapat menyelesaikan Program Pengabdian pada masyarakat sebagai berikut :

1. Bagaimana mengembangkan dan membentuk sekelompok masyarakat yang mandiri secara ekonomis.

2. Bagaimana menerapkan teknologi informasi dan social media internet untuk membantu pemasaran pengrajin miniatur.

3. Bagaimana mengimplementasikan teknologi informasi melalui e commerce.

\section{METODE}

Adapun metode yang dilaksanakan dalam kegiatan Pengabdian Kepada Masyarakat ini adalah :

1. Analisa Keadaaan Masyarakat pengrajin Miniatur Menara.

Salah satu industri rumah tangga yang banyak mendapat sorotan dari segi lingkungan di Desa Bacin adalah industri kerajinan miniatur menara dari bahan kayu. Semakin pesatnya perkembangan industri kecil soufenir, akan berdampak positif bagi kemajuan yang membawa peningkatan pendapatan ekonomi masyarakat kecil. Industri kerajinan miniature menara yang terletak di Desa Basin Kecamatan Kota Kabupaten Kudus 
ini merupakan kategori industri kecil atau industri rumah tangga.

2. Studi literatur

Untuk memperkuat ide yang sudah ada maka kami melakukan studi literature dari buku-buku, artikel-artikel baik dari internet maupun jurnal ilmiah serta data-data pengrajin kerajinan Miniatur Menara di Desa Bacin kab.Kudus.

3. Analisa kebutuhan sistem

Berdasarkan keterangan dari pengrajin tersebut kegiatan pemasaran masih dilakukan dengan cara manual, belum ada penerapan teknologi. Dengan cara manual maka otomatis penjualan akan sedikit karena hanya menggandalkan konsumen datang. Maka dari itu harus diterapkan sebuah sistem informasi yang dapat memudahkan proses penjualan dengan media social internet.

4. Perancangan dan Pembuatan Sistem

5. Pengujian sistem

Pengujian ini dimaksudkan untuk memastikan bahwa kinerja masing-masing sistem dari hasil pembuatan perangkat keras maupun perangkat lunak dapat berfungsi sesuai dengan yang diharapkan.

6. Pendampingan dan sosialisasi. Kami melakukan pengujian, pendampingan serta sosialisasi kepada pengrajin sehingga dapat menggunakan dan memaksimalkan sistem tersebut.

\section{HASIL DAN PEMBAHASAN}

Pendampingan dan pelatihan Iptek bagi masyarakat dan implementasinya pada pengrajin Miniatur Menara ini merupakan kegiatan pengabdian kepada masyarakat yang dilakukan sebagai salah satu bentuk pelaksanaan Tri Dharma Perguruan Tinggi. Kegiatan ini dilaksanakan pada bulan Juli sampai Agustus 2018 selama enam kali pertemuan. Pertemuan pertama dengan materi pengenalan secara keseluruhan tentang peranan teknologi informasi komputer kepada mitra pengrajin, pertemuan kedua dengan materi tahap-tahap mengenal internet dan pengelolaan website, pertemuan ketiga tim pengabdian melakukan evaluasi terhadap mitra dalam pengenalan internet, pertemuan keempat dengan materi praktek mengoperasionalkan internet dan e commerce, sedangkan pertemuan ke lima evaluasi mitra terhadap penggunaan internet untuk menunjang usahnya, Pertemuan keenam tim melakukan pemberdayaan mitra untuk rencana kelanjutan program. Hasil kegiatan pengabdian ini ada beberapa program yang diterapkan :

a. Memberikan informasi bahwa produkproduk miniature menara dapat diterapkan dengan teknologi sesuai dengan kebutuhan yang diharapkan.

b. Melakukan pendampingan dengan penerapan media sosial sebagai sarana pemasaran jual beli secara online.

c. Memberikan kemudahan bagi mitra pengrajin dalam berkomunikasi dengan konsumen.

d. Dengan teknologi internet ini dapat melakukan proses pemasaran tanpa didampingi oleh pakar IT

e. Melatih pengrajin kerajinan miniatur menjadi mandiri dan melakukan pemasaran hingga tingkat nasional.

Sedangkan hasil luaran dari teknologi tepat guna adalah Software aplikasi media marketing yang digunakan untuk memenuhi kebutuhan pemasaran pengrajin dan customer. Berikut ini bentuk aplikasi diimplementasikan:

1. Mendaftarkan pada aplikasi untuk regestrasi tahap awal seperti pada Gambar 1.

\section{Daftar}

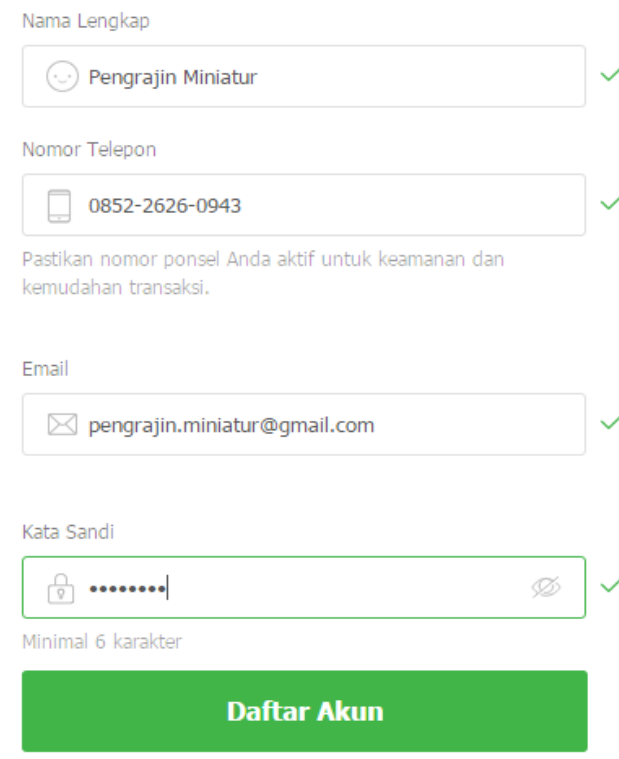

Gambar 1. Registrasi tahap awal

2. Form verifikasi keamanan, untuk meningkatkan keamanan website Langkah selanjutnya yaitu membuat atau create account, lalu mengisi informasi yang dibutuhkan untuk mengupload product yaitu miniature menara kudus. 
3. Mengisi form deskripsi tentang miniature menara kudus seperti pada Gambar 2.

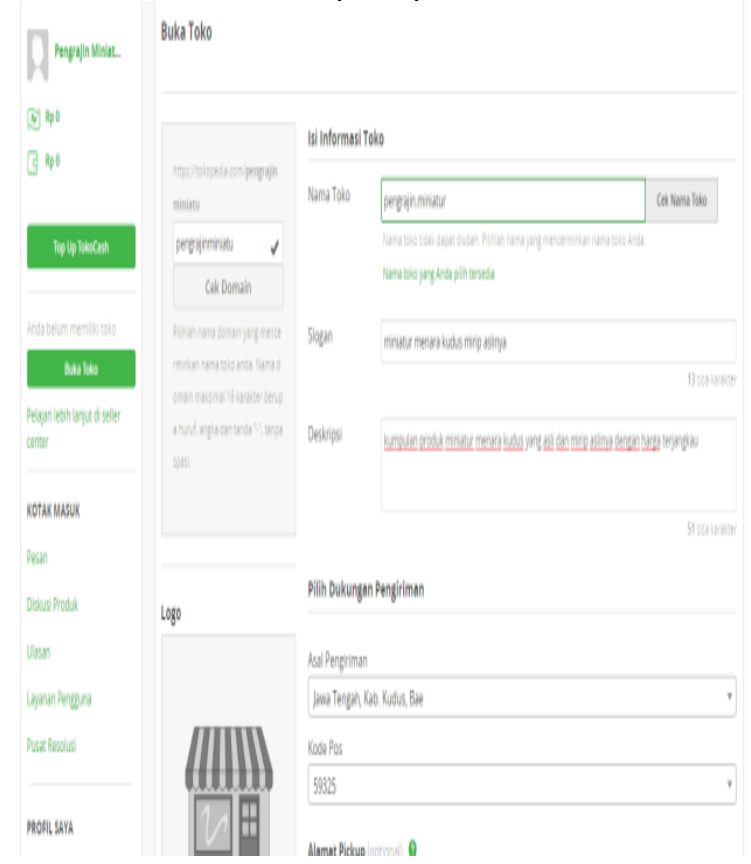

Gambar 2. Form deskripsi tentang miniature menara kudus

4. Mengisi form lokasi penjemputan barang atau denah lokasi pembuatan miniature menara kudus.

5. Pemilihan pengiriman saat memesan miniature menara kudus seperti pada Gambar 3.

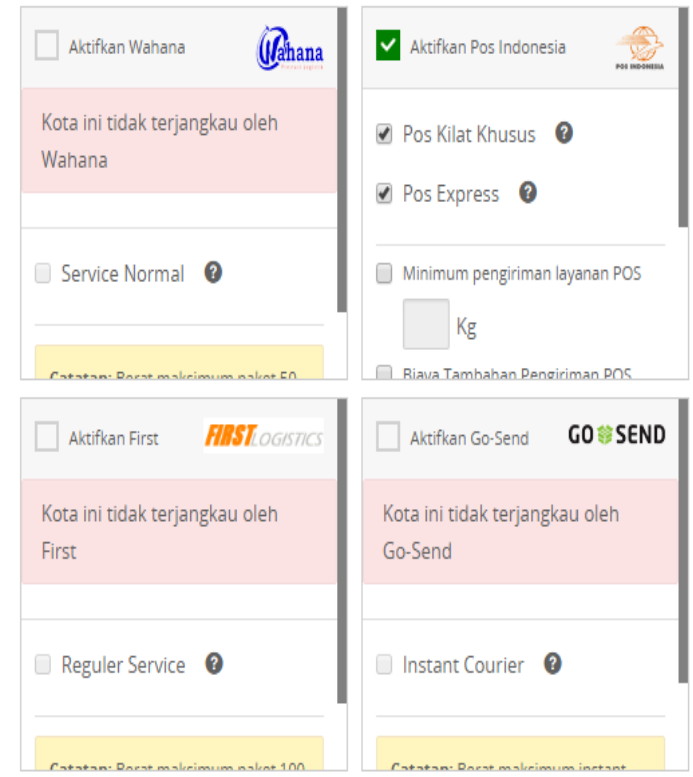

Gambar 3. Pemilihan pengiriman

6. Klik buka toko untuk mensetujui apabila owner.
7. Tampilan toko anda dapat di akses pada urlhttps://www.tokopedia.com/pengrajinmi niatur.

8. Mengisi form untuk menambah barang

9. Form untuk menambahkan gambar barang atau produk yang ingin dipasarkan seperti pada Gambar 4.

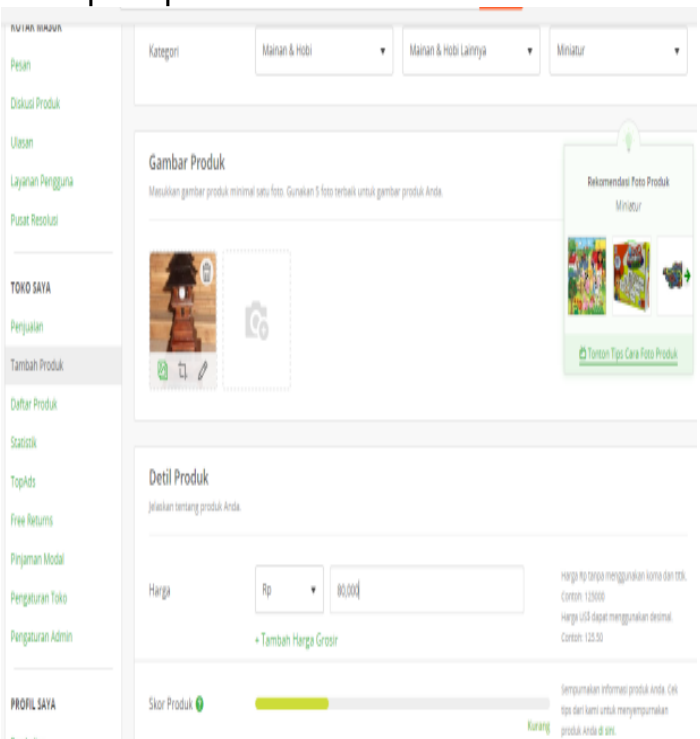

Gambar 4. Form untuk menambahkan gambar barang atau produk

10.Mengisi form deskripsi produk, agar customer mengetahui product secara rinci

11. Halaman form selanjutnya (rincian product). Tampilan product miniature menara kudus yang dilihat oleh customer seperti pada Gambar 5.

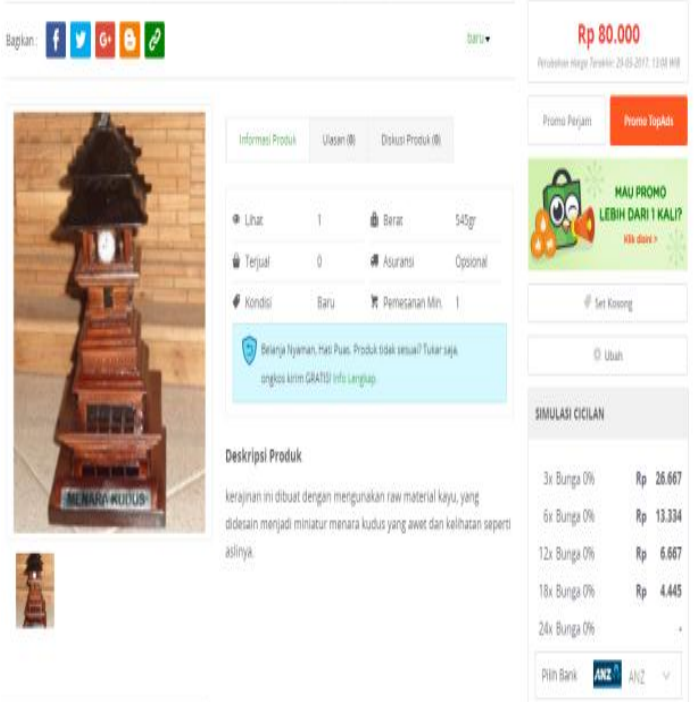

Gambar 5. Form rincian produk 


\section{SIMPULAN DAN SARAN}

Berdasarkan hasil penelitian dapat Membangun Jaringan Usaha (networking), merupakan solusi pada permasalahan yang dihadapi oleh pengrajin miniature menara dalam menghadapi ekonomi globalisasi. Kemampuan SDm yang terbatas dalam penguasaan IT. Perlu adanya dukungan pemerintah pusat, pemerintah daerah, instansi terkait dan pengusaha terhadap para pengrajin kecil agar dapat memenangkan persaingan pasar global. Jaringan Bisnis dalam domain Teknologi Informasi akan mendukung UMKM dalam menjalankan bisnis UMKM dan akan berkembang lebih pesat karena memperluas jaringan.

\section{DAFTAR PUSTAKA}

Ahamad N. S., Musa R., Harun M.H.M., (2015). The Impact of Social Media Content Marketing (SMCM) towards Brand Health. Fifth international conference on marketing and retailing ( $5^{\text {th }}$ incomar).

Fiati.,R., Wijayanti.,E.,2017. Ipteks bagi Masyarakat Kerajinan Miniatur di Desa Bacin Kab.Kudus, Laporan pengabdian Masyarakat, Universitas Muria Kudus.

Fiati,R., Zuliyati. 2016. Strategi Pengembangan Jaringan Usaha UMKM Pigura Kaligrafi Memasuki Pasar Ekspor, Jurnal Flipmas DIANMAS Jawa Tengah,Vol 5, No 1 (2016): April 2016.

Cahyaningrum S.E., dkk, 2017, IbM Pelaku Usaha Bawang Merah Goreng di Jatirejo Nganjuk, Junal ABDI Vol.4 No.2 Januari 2019,hal.91-97.

Stephen, Andrew T., 2016, The role of digital and social media marketing in consumer behavior, Current Opinion in Psychology, 10:17-21. 